\title{
Changing patterns of thyroid cancer in Sri Lanka. Has the iodination programme helped?
}

\author{
PCA Ratnatunga', SC Amarasinghe ${ }^{2}$ and NVI Ratnatunga ${ }^{3}$
}

(Index words: Histological types, pre-existing goitre, extent of spread)

\begin{abstract}
Objectives To ascertain if there has been a change in the pattern of thyroid cancer in Sri Lanka. If so, whether there is a correlation to the implementation of the programme of iodination.
\end{abstract}

Design Retrospective (1974-1986) and prospective (1987-2001)

Setting Kandy Hospital (1974-1982), Peradeniya Hospital (1982-2001) and private hospitals in Kandy (1979-2001).

Method Three hundred consecutive patients with cancer of the thyroid seen over 28 years (1974-2001) period were reviewed for demography, histopathology and extent of spread at presentation. Seventy one patients of this group had a pre-existing goitre of greater than 10 years' duration and were similarly reviewed.

Results A highly significant reduction of anaplastic thyroid cancer and a highly significant reduction in the extent of extra-thyroidal spread at presentation of differentiated thyroid cancer were observed after 1995. In malignancy supervening on pre-existing goitre, a significant reduction in anaplastic carcinoma and a highly significant increase in papillary carcinoma were noted in the post-1996 period. A significant reduction of extra-thyroidal spread was also observed.

Conclusion A trend towards more differentiated thyroid cancer with lesser degree of spread was observed in recent years. The iodination programme implemented in 1995 is likely to be responsible for this change.

\section{Introduction}

An audit of thyroid illness on patients attending the first author's surgical clinic has shown an increasing prevalence of thyroiditis and thyrotoxicosis since the mid 1990s. Such changes occur after iodination programmes $[1,2]$. Could the nature of thyroid cancer too be undergoing change, and if so, what changes in the current therapeutic protocols must be effected? We sought answers.

\section{Patients and method}

Three hundred consecutive patients with cancer primarily involving the thyroid gland managed by the first author in General Hospital Kandy (1974-81), General Hospital Peradeniya (1982-2001) and in the private sector hospitals in Kandy (1979-2001) over a 28-year period were reviewed. Patient data for the early period (19741986) were collected and collated retrospectively from well maintained records, and supplemented by data from patient notes and clinic files. In 1986 an ongoing protocol based prospective audit was established. The data was digitised and audited on an Excel spreadsheet.

The 300 patients were divided for purposes of this study into three equal cohorts with 100 consecutive patients in each. They were seen over the periods 1974 1986, 1987-1995 and 1995-2001.

Papillary follicular carcinoma was classified with papillary carcinoma. In the retrospective group (19741986) detailed data of the extent of spread was not always available. Staging of thyroid cancers and separation into high-risk and low-risk prognostic groups in differentiated thyroid carcinoma were based on the TNM classification [3]. Thyroid cancer in multinodular goitres, i.e. goitre present for $>10$ years were studied with approximately equivalent number of patients, over three time periods 1981-1991 ( $\mathrm{n}=25), 1992-1996(\mathrm{n}=23), 1997-2001$ $(n=23)$.

The data were analysed using appropriate statistical tests.

\section{Results}

Table 1 shows the prevalence of the dominant histological patterns in the three groups of patients over the specified times. A highly significant reduction of anaplastic tumours versus differentiated tumours in recent years was observed.

The others $(n=15)$ referred to in the table include lymphomas $(n=5)$, papillary carcinomas with squamous differentiation $(n=3)$, a squamous carcinoma and a mucoid carcinoma of the thyroid. In five thyroid malignancies, specific histological type of malignancy was not available.

Table 2 shows the extent of spread at presentation of differentiated (i.e. papillary and follicular) thyroid cancer seen in the respective periods. An increase in diagnosis of differentiated tumours without extrathyroidal spread after the mid 1990s is a highly significant feature $(p<0.001)$. In view of the wide prognostic differences associated with the age of onset of differentiated

${ }^{1}$ Professor, ${ }^{2}$ Research Assistant, Department of Surgery and ${ }^{3}$ Professor, Department of Pathology, University of Peradeniya Correspondence: PCA, Tel: 9408 223918, e-mail: kesara7@yahoo.com (Competing interests: none declared). Received 5 May and revised version accepted 11 October 2003 
Table 1. Relative prevalence of different histological types of thyroid cancer in each time cohort

\begin{tabular}{lccc}
\hline Histological type & $\begin{array}{c}1974-1986 \\
n=100\end{array}$ & $\begin{array}{c}1987-1995 \\
n=100\end{array}$ & $\begin{array}{c}1995-2001 \\
n=100\end{array}$ \\
\hline $\begin{array}{l}\text { Papillary and } \\
\text { Papillary follicular }\end{array}$ & 35 & 34 & 56 \\
Follicular & 25 & 44 & 31 \\
Medullary & 2 & 6 & 4 \\
Anaplastic & 33 & 10 & 5 \\
Others & 5 & 6 & $4(\mathrm{p}<0.001)$ \\
\hline
\end{tabular}

risk prognostic groups in two time based cohorts is noted. As can be seen in Table 3, in those over 45 years, the high-risk group during the period 1974-1993, 41 out of $59(69.5 \%)$ decreased to 27 out of $46(58.7 \%)$ during the 1994-2001 period. The overall high risk 41/106 (38.67\%) reduced to $27 \%$. On comparing proportions these findings do not reach significance.

The prevalence of clinical carcinoma versus incidental carcinoma discovered thyroids operated on, is given in Table 4. No significant difference was observed. Histology of the thyroid carcinoma in such incidentelomas, i.e. the papillary/follicular ratio was 3:4 and 5:2 in the 1974-1994 and 1995-2001 periods respectively. An increasing trend towards papillary and papillary follicular in the post-1995 period is seen.

Table 2. Time based cohort study of the extent of spread of differentiated* thyroid carcinoma at presentation

\begin{tabular}{lcccccc}
\hline Extent & $1974-1978$ & $1979-1983$ & $1984-1988$ & $1989-1993$ & $1994-1998$ & $1999-2001$ \\
& $\%=6$ & $n=17$ & $n=38$ & $n=57$ & $n=51$ & $n=54$ \\
\hline $\begin{array}{l}\text { Intra-thyroidal } \\
\text { Extra-thyroidal }\end{array}$ & 0 & 23.5 & 26.3 & 28.1 & 52.9 & 44.4 \\
- Direct & & & & & & \\
- Lymphatic & 16.6 & 29.4 & 31.6 & 29.8 & 29.4 & 25.9 \\
- Metastatic & 83.3 & 41.2 & 39.5 & 31.6 & 21.6 & 25.9 \\
\hline
\end{tabular}

*Excluding medullary carcinoma

Table 3. Differentiated thyroid carcinoma*: stage at presentation

\begin{tabular}{lcccccccc}
\hline & & \multicolumn{3}{c}{$1974-1993$} & \multicolumn{3}{c}{ 1994-2001 } \\
\cline { 3 - 8 } & & Stage & \multicolumn{2}{c}{ Age groups (years) } & \multicolumn{2}{c}{ Age groups (years) } \\
& & 45 & $>45$ & $\begin{array}{c}\text { Total } \\
n=106\end{array}$ & 45 & $>45$ & $\begin{array}{c}\text { Total } \\
n=100\end{array}$ \\
\hline Low & I & 43 & 6 & 49 & 53 & 5 & 58 \\
risk & II & 4 & 12 & 16 & 1 & 14 & 15 \\
\hline High & III & 0 & 17 & 17 & 0 & 13 & 13 \\
risk & IV & 0 & 24 & 24 & 0 & 14 & 14 \\
& Total & 47 & 59 & 106 & 54 & 46 & 100 \\
\hline
\end{tabular}

*Medullary and other non-thyroid cell carcinomas were excluded

thyroid carcinoma, a review of the age and the stage at presentation based on the TNM classification is given in Table 3. Further, the relative prevalence of high and low
Table 4. Prevalence of incidental carcionomas in the two periods

\begin{tabular}{lcc}
\hline & $1974-1994$ & $1995-2001$ \\
\hline Clinical carcinoma & 181 & 112 \\
Incidentelomas & 7 & 7 \\
$\%$ & 3.7 & 5.8 \\
\hline
\end{tabular}

\section{Cancer in multinodular goitre}

In 71 of the 300 patients with thyroid cancer at presentation, a pre-existing goitre of at least 10 years duration was described (Table 5). In $66 \%$ of the 71 , the goitre had been present for 15 or more years. Table 6 shows the histological patterns of tumour in the cohorts selected. A highly significant $(\mathrm{p}<0.001)$ increase in the prevalence of papillary cancer from $6.3 \%$ in the pre-1996 period to a $39 \%$ in the post-1996 period is observed. A significant reduction in the prevalence of anaplastic tumours from $25 \%$ to 0 is also a feature in such malignant 
transformations during these periods. Only three patients in the group of 71 had a tumour equal to or smaller than $1.5 \mathrm{~cm}$. Table 7 indicates the extent of the tumour at presentation in patients with multinodular goitre. A significant $\mathrm{X}^{2} 6.8 \mathrm{df}_{2}(\mathrm{p}=0.033)$ reduction in the prevalence of extra-thyroidal spread has been observed more recently in patients with malignant transformation of their goitres.

Table 5. The prevalence of pre-existing goitre (>10 years) in patients with thyroid cancer

\begin{tabular}{lccc}
\hline $\begin{array}{l}\text { Year groups } \\
\text { Goitre duration (years) }\end{array}$ & $\begin{array}{c}1974-1991 \\
n=25\end{array}$ & $\begin{array}{c}1992-1996 \\
n=23\end{array}$ & $\begin{array}{c}1997-2001 \\
n=23\end{array}$ \\
\hline $10-14$ & 11 & 5 & 8 \\
$15-19$ & 3 & 5 & 4 \\
$20-24$ & 4 & 6 & 4 \\
$25-29$ & 3 & 5 & 0 \\
$30-34$ & 3 & 1 & 1 \\
$35+$ & 1 & 3 & 4 \\
\hline
\end{tabular}

Table 6. Histological types of malignancy in multinodular goitres ( $>10$ years duration)

\begin{tabular}{lccc}
\hline & $1974-1991$ & $1992-1996$ & $1997-2001$ \\
\hline Papillary & 1 & 2 & 9 \\
Papillary follicular & 0 & 5 & 4 \\
Follicular & 13 & 11 & 9 \\
Anaplastic & 9 & 3 & 0 \\
Medullary & 1 & 0 & 0 \\
Other & 1 & 2 & 1 \\
$\mathrm{n}$ & 25 & 23 & 23 \\
\hline
\end{tabular}

Table 7. Thyroid cancer in multinodular goitre of $>\mathbf{1 0}$ years duration and extent of growth

\begin{tabular}{lccc}
\hline Extent & $\begin{array}{c}1974-1991 \\
n=25\end{array}$ & $\begin{array}{c}1992-1995 \\
n=23\end{array}$ & $\begin{array}{c}1996-2001 \\
n=25\end{array}$ \\
\hline Intrathyroid & 3 & 9 & 11 \\
Extrathyroid: & 22 & 14 & 14 \\
$\bullet \quad$ Direct & 8 & 10 & 8 \\
$\bullet \quad$ Lymphatic & 7 & 10 & 2 \\
$\bullet \quad$ Metastatic & 12 & 9 & 6 \\
\hline
\end{tabular}

\section{Discussion}

Geographical variation in the nature of thyroid carcinoma is well documented [4]. Anaplastic tumours are of high prevalence in iodine deficient areas [5]. It is hypothesised that this may be due to chronic stimulation of the thyroid by TSH [6]. Yet others claim that the unquestioning acceptance of the presence of a goitre in the neck of people in endemic areas delays diagnosis and permits the somewhat indolent differentiated tumours to transform to undifferentiated tumours [6,7].

Several studies have shown that iodination programmes cause prevalence of aggressive tumours to dwindle and present earlier [8], a dramatic and salutary response. The data presented in our study appear to reflect a similar response.

The iodination programme in Sri Lanka was formally initiated in 1995. Though several attempts were made previously, they were unsuccessful due to social unrest in the country. Two thirds of salt produced in Sri Lanka are iodised by inappropriate measures adopted by small scale private producers [9]. However, the median iodine content of salt sampled from all provinces (except the North) did not show a wide variation [9], with a natural mean of $30.7 \mathrm{ppm}$, which was considered satisfactory [9].

Table 1 shows a highly significant decline in aggressive tumours beginning in the late 1980s and accelerating in the late 1990s. Further, when one reviews differentiated thyroid carcinoma (Table 2) an increasing prevalence of early tumours is seen after 1994 which could be consequent to iodination.

When we reviewed age-based data on differentiated thyroid cancer using the widely accepted TNM classification (Table 3) a lower prevalence of high-risk groups is noted post-1994, which did not reach statistical significance. Though the prevalence of "incidental" carcinoma when compared to clinical carcinoma (Table 6) had not changed, the nature of cancerous transformation in multinodular goitre has changed to less aggressive tumours with a reduced extent of spread at presentation (Table 7).

Anaplastic carcinoma of the thyroid is considered one of the most rapidly progressing soft tissue malignancies. It is dominantly seen in the over 60-year age group. Despite the demographic increase in this age group, the reduction in prevalence is significant and suggests dramatic decline in both morbidity and mortality for carcinoma of the thyroid in Sri Lanka.

Medullary carcinomas remain unaffected by iodination, being derived from parafollicular cells that take no part in iodine metabolism. The numbers of medullary carcinoma in this study are too small to make any valid conclusions.

Rats and mice starved of iodine or fed on goitrogenic food developed thyroid cancer [10,11]. Experimentally, iodine deficiency increases the growth response of normal thyroid tissue to thyroid stimulating hormone (TSH) [12]. 
However, no consistent elevation of TSH has been observed in humans with thyroid carcinoma [13]. Many endemic goitre regions have populations with chronically increased TSH levels. One such endemic region well studied is Cali, in Colombia, where a high prevalence of cancer has been established [4,5]. The tumours seen in such endemic regions are more aggressive, i.e. anaplastic or follicular [4]. In contrast, in countries such as Iceland where high dietary iodine is known to be associated with a low TSH level in the population, a high prevalence of papillary carcinoma is noted [15].

Some authors working in iodine rich areas such as Iceland suggest that TSH could play different roles encouraging papillary carcinoma in iodine rich areas and follicular carcinoma in areas with iodine deficiency. The papillary follicular ratio in our study was $1.4: 1 ; 0.8: 1$ and 1.8:1 in 1974-1987 in 1987-1995 and 1995-2001 respectively. The figures are similar to those from iodine deficient Cali in Colombia [3], 1.3:1. In Salta, the Argentina ratio increased from 1.7:1 to 3.1:1.2. The slight improvement in the last 10 years may be heralding this change that seems to be present in countries such as Scotland (3.5:1) and Iceland (6.5:1) where iodine availability is sufficient or even in excess [15].

In conclusion, there seems to be sufficient clinical data to suggest that the morbidity and mortality from thyroid carcinoma could be decreasing and that iodination of salt may be responsible for this change.

\section{Acknowledgements}

I acknowledge Professor RG Panabokke for histopathology in the early years, Dr. Kumarasiri for the statistical analysis and Mr. Chandana Jayasundara for typing the evolving script.

\section{References}

1. Marwaha RL, Tandon N, Karak AK, Gupta N. Verma K, Kochupillai N. Hashimoto's Thyroiditis; Countrywide screening of goitrous healthy young girls in post-iodization phase in India. Journal of Clinical Endocrinology and Metabolism 2000; 85: 3798-802.
2. Harach HR, Williams ED. Thyroid cancer and thyroiditis in goitrous region of Salta, Argentina, before and after iodine prophylaxis. Clinical Endocrinology (Oxford) 1995; 43: 701-6.

3. Hermanek P, Sobin LH, eds. Thyroid Gland. TNM Classification of Malignant Tumours. 4th ed. Berlin Germany: Springer-Verlag.

4. Cuello C, Correa P, Eisenberg H. Geographic pathology of thyroid carcinoma. Cancer 1969; 23: 230-9.

5. Wahner HW, Cuello C, Correa P, Uribe LF, Gaitan E. Thyroid carcinoma in an endemic goitre area Cali, Columbia. American Journal of Medicine 1955; 40: 58-66.

6. Riccabona G. Thyroid cancer and endemic goitre. In: Stanbury JB, Hetzel BS, eds. Endemic Goitre and Endemic Cretinism, Iodine Nutrition in Health and Disease. New Delhi: Wiley Eastern Ltd, 1987: 333-50.

7. Spires JR, Schatz MR, Miller RH. Anaplastic thyroid carcinoma associated with differentiated thyroid carcinoma. Archives of Otolaryngology and Head and Neck Surgery 1988; 114: 40-4.

8. Roher HD, Goretzki PE. Management of goitre and thyroid nodules in an area of endemic goitre. Surgical Clinics of North America 1987 67: 233-49.

9. Jayatissa R. Iodine content of salt in iodine deficiency status of children in Sri Lanka. 2000-2001. Medical Research Institute, Department of Health Services, Sri Lanka 2001.

10. Axelard AA, Leblond CP. Induction of thyroid tumours in rats by a low iodine diet. Cancer 1955; 8: 339-57.

11. Money WI, Rawson RW. The experimental production of thyroid tumours in rats exposed to prolonged treatment with thiouracil. Cancer 1950; 3: 321-8.

12. Bray GA. Increased sensitivity of the thyroid in the iodine depleted rats to the goitrogenic effects of thyrotrophin. Journal of Clinical Investigation 1968; 47: 1640-7.

13. Taylor S. Carcinoma of the thyroid gland. Journal of the Royal College of Surgeons of Edinburgh 1969; 14: 183-92.

14. In Endemic Goitre and cretinism, continuing threats to world health. PAHO Sci Pub no. 292, 1974, 43.

15. Williams ED, Doniach I, Bjarnason O. Thyroid cancer in an iodine rich area. Cancer 1977; 39: 215-22. 